\title{
Pain severity is associated with muscle strength and peak oxygen uptake in adults with fibromyalgia
}

This article was published in the following Dove Press journal:

Journal of Pain Research

3 May 2014

Number of times this article has been viewed

\author{
W Michael Hooten ${ }^{1,2}$ \\ Jolene M Smith ${ }^{3}$ \\ Jason S Eldrige \\ David A Olsen ${ }^{3}$ \\ W David Mauck' \\ Susan M Moeschler' \\ 'Department of Anesthesiology, \\ ${ }^{2}$ Department of Psychiatry and \\ Psychology, Mayo Clinic College \\ of Medicine, ${ }^{3}$ Mayo School of \\ Graduate Medical Education, \\ Rochester, MN, USA
}

Correspondence: W Michael Hooten Department of Anesthesiology, Mayo Clinic College of Medicine, 200 First St SW, Rochester, MN 55905, USA

Tel + I 5072669877

Email hooten.william@mayo.edu
Background: The associations between pain, lower extremity strength, and aerobic conditioning have not been widely investigated in adults with fibromyalgia (FM). The principle objective of this study was to investigate the relationship between pain severity and knee strength in patients seeking treatment for FM. A secondary objective was to investigate the relationship between pain scores and aerobic conditioning.

Methods: Three measures of knee strength (isokinetic extensor, isokinetic flexor, isometric extensor) were quantified in the dominant leg of 69 adults with FM using a dynamometer at speeds of 60 degrees per second $\left(60^{\circ} / \mathrm{s}\right)$ and $180 \%$ s. Peak oxygen uptake $\left(\mathrm{VO}_{2}\right)$ was assessed using a cycle ergometer, and pain was assessed using the pain severity subscale of the Multidimensional Pain Inventory.

Results: In univariable linear regression analyses using pain severity as the dependent variable, lesser values of isokinetic knee extensor strength at $60 \% \mathrm{~s}(P=0.041)$ and $180 \% \mathrm{~s}(P=0.010)$, isokinetic knee flexor strength at $60 \% \mathrm{~s}(P=0.028)$ and $180 \% \mathrm{~s}(P=0.003)$, and peak $\mathrm{VO}_{2}$ uptake $(P=0.031)$ were predictive of greater pain severity scores. In multiple variable linear regression models adjusted for age, sex, body mass index, and opioid use, the following associations retained statistical significance; isokinetic knee extensor strength at $60 \% \mathrm{~s}(P=0.020)$ and $180 \% \mathrm{~s}$ $(P=0.003)$, isokinetic knee flexor strength at $60 \% \mathrm{~s}(P=0.015)$ and $180 \% \mathrm{~s}(P=0.001)$, and peak $\mathrm{VO}_{2}$ uptake $(P=0.014)$. However, no significant associations were found between pain severity and isometric knee extensor strength.

Conclusion: The main findings from this study were that lesser values of isokinetic knee strength and peak $\mathrm{VO}_{2}$ uptake were predictive of greater pain severity scores. These results build on the findings of previous investigations, but ongoing research is needed to further characterize the effects of strength and peak $\mathrm{VO}_{2}$ uptake on the pathophysiology of FM.

Keywords: fibromyalgia, knee extensor strength, knee flexor strength, isokinetic, peak oxygen uptake

\section{Introduction}

Fibromyalgia (FM) is characterized by the presence of diffuse widespread pain. ${ }^{1}$ Previous studies suggest FM is also associated with reduced knee strength ${ }^{2-4}$ and decreased levels of aerobic conditioning. ${ }^{5,6}$ Knee strength has been preferentially used because of its critical role in performing routine functional tasks, and easy accessibility of the lower extremity for strength testing. However, the associations between pain, lower extremity strength, and aerobic conditioning have not been widely investigated in adults with FM.

In a previous randomized equivalence trial, pain severity, knee strength, and aerobic conditioning measured as the peak uptake of oxygen $\left(\mathrm{VO}_{2}\right)$ were quantified in 
a group of patients seeking treatment for FM. ${ }^{7}$ A secondary analysis of this data set found a relationship between knee extensor strength and pressure pain thresholds whereby greater knee strength (isokinetic extensor, isometric extensor) was predictive of higher pressure pain thresholds in univariable linear regression analyses and multivariable linear regression models adjusted for pain and other clinical factors including $\mathrm{VO}_{2}$, age, sex, and body mass index. ${ }^{8}$ These findings suggested greater muscle strength had a favorable impact on pressure pain thresholds, and the effect persisted after adjusting for pain severity. Pressure pain threshold is defined as the quantity of pressure needed to elicit pain, and was measured using a hand-held electronic algometer fitted with a $1.0 \mathrm{~cm}$ diameter foot plate. Muscle strength was measured using a dynamometer at rotational rates of 60 degrees per second $\left(60^{\circ} / \mathrm{s}\right)$ and $180 \% \mathrm{~s}$, but the $180 \%$ s rotational data have not been previously reported. In addition, the relationships between pain, strength, and $\mathrm{VO}_{2}$ have not been investigated. Therefore, the principal objective of this study was to further investigate the relationship between pain severity and knee strength in patients seeking treatment for FM. A secondary objective was to investigate the relationship between pain scores and aerobic conditioning measured as $\mathrm{VO}_{2}$. The current study represents a further secondary analysis of previously published data. ${ }^{7,8}$

\section{Materials and methods}

\section{Study participants}

The Mayo Foundation Institutional Review Board approved the study, and written informed consent was obtained from all patients. The trial is registered at ClinicalTrials.gov (identifier NCT01253395). ${ }^{9}$ As previously reported, ${ }^{7,8}$ patients were identified upon admission to the 3-week outpatient interdisciplinary pain treatment program from April 2006 to February 2008. Seventy-two patients participated in the study, and 69 completed the baseline assessment. Inclusion criteria included a diagnosis of FM using the American College of Rheumatology 1990 criteria and age older than 18 years. ${ }^{10}$ Exclusion criteria included the presence of an underlying disease process that could compromise the patient's ability to perform strength testing and undergo an assessment of aerobic capacity. Examples of such diseases include ischemic heart disease, chronic obstructive pulmonary disease, severe knee or hip osteoarthritis, and rheumatoid arthritis. Other exclusion criteria included pregnancy and severe psychiatric illness including a psychotic disorder (schizophrenia, schizoaffective disorder) and dementia.

\section{Baseline demographic and pain characteristics}

As previously reported, ${ }^{7,8}$ age, sex, ethnicity, body mass index, current employment, duration of pain, current marital status, educational level, and current opioid use were determined upon admission to the 3 -week pain treatment program.

\section{Extensor and flexor knee strength}

As previously described, ${ }^{7,8}$ on day 1 after admission to the 3-week pain treatment program, extensor and flexor knee strength was measured in a specialized biomechanics facility at our institution. A dynamometer (Biodex Medical Systems, Shirley, NY, USA) was used to measure three aspects of knee strength (isometric extensor, isokinetic extensor, isokinetic flexor) using the dominant leg of each patient. The hip joint of each patient was aligned between 90 and 100 degrees of flexion in the sitting position. The position of each patient was fixed at the level of the torso, hips, and upper thighs. ${ }^{11}$ After aligning the knee with the lever arm, the ankle was secured to the lever arm. With the knee positioned at 90 degrees flexion, isokinetic strength testing was performed by having all patients maximally contract the knee extensors and then the knee flexors in a rapidly repeating motion at rates of 60 degrees per second $(60 \%)$ and $180^{\circ} / \mathrm{s}$. For isometric knee extensor strength testing, the knee was secured at 60 degrees flexion and patients maximally contracted the knee extensors. A sequence of five successive contractions was completed for each test with a one-minute break between each sequence. The results of all tests were corrected for the effects of gravity. The maximal torque documented for each sequence of five successive contractions was recorded.

\section{Peak aerobic capacity}

As previously reported, ${ }^{7,8}$ peak $\mathrm{VO}_{2}$ uptake was assessed on day 2 after admission to a specialized facility using a cycle ergometer. ${ }^{11}$ During testing, blood pressure measurements were performed, and the patient was continuously monitored using a 12-lead electrocardiogram. Following a 3-minute period of cycling at a workload of $25-50 \mathrm{~W}$, the amount of work was increased every minute by $10-25 \mathrm{~W}$ until the patient had to stop due to fatigue. The greatest value of oxygen uptake that occurred within the last 30 seconds of the testing protocol was used as the measure of peak $\mathrm{VO}_{2}$ and expressed in units of $\mathrm{mL} / \mathrm{kg}$ per minute. A mass spectrometer (Perkin Elmer, Waltham, MA, USA) was used to analyze expired gases. 


\section{Pain severity}

As previously reported, ${ }^{7,8}$ pain was assessed on day 1 after admission using the Multidimensional Pain Inventory pain severity subscale. ${ }^{12}$ The pain severity subscale has been shown to be a reliable and valid measure of clinical pain, ${ }^{13}$ and is comprised of three questions where the patient is asked to rate their current level of pain, their average level of pain over the past week, and their level of current painrelated suffering. The response to each question is rated on a seven-point scale; a score of 0 denotes no pain or suffering and a score of 6 denotes severe pain or suffering. Scores were transformed to standardized T-scores (mean 50, range 0-100, standard deviation 10) where higher scores denote greater levels of pain and suffering. ${ }^{14}$ We have used this subscale as an outcome measure in patients with fibromyalgia. ${ }^{15,16}$

\section{Data analysis}

Demographic information and pain-related clinical factors were compiled. Means \pm standard deviations were calculated for continuous variables, and count (with proportion) was calculated for categorical variables. Univariable linear regression analysis was conducted using pain severity (dependent), muscle strength (independent), and peak $\mathrm{VO}_{2}$ uptake (independent) as variables. Multiple variable linear regression analysis (adjusted for age, sex, body mass index, opioid use) was then conducted using the same dependent and independent variables. The multiple variable models were adjusted using the specified cofactors because these clinical factors have been shown to impact FM-related pain and physical functioning. ${ }^{2,6,15-20}$ Statistical significance of all tests was accepted at $P<0.05$ (PASW version 18.0, IBM Corporation, Armonk, NY, USA).

\section{Results \\ Demographics}

Table 1 contains the demographic information and pain-related clinical factors for the group of FM patients. The patients were predominantly married Caucasian females who were not working and had a mean pain duration in excess of 12 years. Twenty-eight percent of patients were using prescription opioids, and the mean morphine equivalent dose was $89.5 \pm 132.2(5-442) \mathrm{mg}$ per day.

\section{Muscle strength and pain severity}

The values of pain severity and muscle strength are presented in Table 2. Table 3 presents the results of the univariable regression analysis where significant associations were observed between pain severity (dependent variable) and isokinetic knee extensor strength at $60 \% \mathrm{~s}(P=0.041)$ and
Table I Demographic and clinical characteristics

\begin{tabular}{ll}
\hline Characteristic* & $\mathbf{( N = 6 9 )}$ \\
\hline Sex $(\mathrm{N}, \%)$ & $63(91.3)$ \\
$\quad$ Female & $6(8.7)$ \\
$\quad$ Male & $46.7 \pm 10.5$ \\
Age (mean $\pm \mathrm{SD})$ & \\
Ethnicity & $66(95.7)$ \\
$\quad$ Caucasian & $\mathrm{I}(\mathrm{I} .4)$ \\
African American & $\mathrm{I}(\mathrm{I} .4)$ \\
Hispanic & $\mathrm{I}(\mathrm{I} .4)$ \\
$\quad$ Other & $30.2 \pm 6.8$ \\
Body mass index $\left(\mathrm{kg} / \mathrm{m}^{2}\right)$ & $46(66.7)$ \\
Married & $2 \mathrm{I}(30.4)$ \\
Currently employed & $14.9 \pm 3.2$ \\
Years of education & $12.2 \pm 12.9$ \\
Pain duration, years & $19(27.5)$ \\
Current opioid use & $89.5 \pm 132.2$ \\
Morphine equivalent dose (mg/day) &
\end{tabular}

Notes: *All data in this table have been previously reported. Adapted from Hooten WM, Qu W, Townsend CO, Judd JW. Effects of strength vs aerobic exercise on pain severity in adults with fibromyalgia: a randomized equivalence trial. Pain. 2012;153(4):915-923. Copyright (c) 2012 International Association for the Study of Pain; Hooten WM, Rosenberg CJ, Eldrige JS, Qu W. Knee extensor strength is associated with pressure pain thresholds in adults with fibromyalgia. PLoS One. 2013;8(4): $559930 .{ }^{8}$

Abbreviation: SD, standard deviation.

$180^{\circ} / \mathrm{s}(P 0.010)$, and isokinetic knee flexor strength at $60^{\circ} / \mathrm{s}$ $(P=0.028)$ and $180^{\circ} / \mathrm{s}(P=0.003)$. In all analyses, lesser values of isokinetic knee extensor and flexor strength were predictive of greater pain severity scores. However, isometric knee extensor strength was not predictive of pain severity. Table 3 also presents the results of the multiple variable analyses where isokinetic knee extensor and flexor strength were found to be predictive of greater pain severity scores.

\section{Pain severity and peak $\mathrm{VO}_{2}$ uptake}

Table 2 contains the summary values of peak $\mathrm{VO}_{2}$ uptake. In univariable linear regression analysis, peak $\mathrm{VO}_{2}$ uptake was significantly associated with pain severity $(B-0.500$;

Table 2 Summary values of pain severity, muscle strength, and peak uptake of oxygen $\left(\mathrm{VO}_{2}\right)$

\begin{tabular}{lc}
\hline Characteristic & FM patients $(\mathrm{n}=6 \mathbf{6 9})$ \\
\hline Pain severity $( \pm$ standard deviation)* & $47.7 \pm 4.2$ \\
Isometric knee extensor $(\mathrm{Nm})^{*}$ & $130.7 \pm 45.0$ \\
Isokinetic knee extensor $60 \% \mathrm{~s}(\mathrm{Nm})^{*}$ & $92.9 \pm 40.3$ \\
Isokinetic knee extensor $180 \% \mathrm{~s}$ & $64.2 \pm 28.1$ \\
Isokinetic knee flexor $60^{\circ} / \mathrm{s}^{*}$ & $53.7 \pm 23.0$ \\
Isokinetic knee flexor $180^{\circ} / \mathrm{s}$ & $45.0 \pm 18.7$ \\
Peak $\mathrm{VO}_{2}$ uptake $(\mathrm{mL} / \mathrm{kg} / \mathrm{min})^{*}$ & $16.5 \pm 4.2$ \\
\hline
\end{tabular}

Notes: *Data have been previously reported. Adapted from Hooten WM, Qu W, Townsend CO, Judd JW. Effects of strength vs aerobic exercise on pain severity in adults with fibromyalgia: a randomized equivalence trial. Pain. 2012;153(4):915-923. ${ }^{7}$ Copyright () 2012 International Association for the Study of Pain; Hooten WM, Rosenberg CJ, Eldrige JS, Qu W. Knee extensor strength is associated with pressure pain thresholds in adults with fibromyalgia. PLoS One. 2013;8(4):e59930.8

Abbreviation: FM, fibromyalgia. 
Table 3 Linear regression analyses of pain severity (dependent variable) and muscle strength (independent variable)

\begin{tabular}{lllll}
\hline Strength (Newton meters) & Univariable B coefficient & $P$-value & Multivariable B coefficient* & $P$-value \\
\hline Isometric knee extensor & $-0.028(95 \% \mathrm{Cl},-0.072$ to 0.016$)$ & 0.203 & $-0.048(95 \% \mathrm{Cl},-0.100$ to 0.003$)$ & 0.066 \\
Isokinetic knee extensor $60 \% \mathrm{~s}$ & $-0.050(-0.098$ to -0.002$)$ & 0.041 & $-0.062(-0.114$ to -0.010$)$ & 0.020 \\
Isokinetic knee extensor $180 \% \mathrm{~s}$ & $-0.090(-0.158$ to -0.022$)$ & 0.010 & $-0.115(-0.188$ to $-0.04 \mathrm{I})$ & 0.003 \\
Isokinetic knee flexor $60 \% \mathrm{~s}$ & $-0.095(-0.179$ to $-0.01 \mathrm{II})$ & 0.028 & $-0.114(-0.205$ to -0.023$)$ & 0.015 \\
Isokinetic knee flexor $180 \% \mathrm{~s}$ & $-0.156(-0.256$ to -0.056$)$ & 0.003 & $-0.184(-0.291$ to -0.077$)$ & 0.001 \\
\hline
\end{tabular}

Note: *Adjusted for age, sex, BMI, and opioid use.

Abbreviations: $\mathrm{Cl}$, confidence interval; $\mathrm{BMI}$, body mass index.

$95 \%$ confidence interval $-0.952,-0.048 ; P=0.031)$ where lesser values of peak $\mathrm{VO}_{2}$ uptake were predictive of greater pain severity scores. In multiple variable regression analysis, the association between lesser values of peak $\mathrm{VO}_{2}$ uptake and greater pain severity retained statistical significance $(B$ $-0.660 ; 95 \%$ confidence interval $-1.183,-0.137 ; P=0.014)$.

\section{Discussion}

The important observations from this study were that lesser values of isokinetic knee extensor strength (at $60 \%$ and $180^{\circ} \%$ ), isokinetic knee flexor strength (at $60 \% \mathrm{~s}$ and $180 \%$ s) and peak $\mathrm{VO}_{2}$ uptake were predictive of greater pain severity scores in univariable and multivariable models adjusted for clinical factors known to impact FM-related pain and physical functioning. However, no significant associations were found between pain severity and isometric extensor knee strength.

Numerous studies have documented improvements in various quality of life measures, including pain, in adults with FM following participation in structured muscle strengthening ${ }^{4,21,22}$ and aerobic exercise ${ }^{6,23-25}$ programs. This is consistent with the findings of our previous randomized equivalence trial where strength and aerobic exercise had equivalent effects on reducing pain in patients with FM. ${ }^{7}$ However, few studies have examined the direct associations between pain and physiological measures of strength and peak $\mathrm{VO}_{2}$ uptake. For example, in a previous investigation involving women with FM randomized to a 32-week aquatic training program, changes in knee flexor strength were significantly associated with improvements in physical functioning, while changes in knee extensor strength were significantly associated with improvements in emotional and mental health functioning, and postural balance. ${ }^{21}$ However, the association between pain and lower extremity strength was not reported. Similarly, in a previous study involving women with FM randomized to an 8-week cardiovascular fitness program, significant changes in pain and peak $\mathrm{VO}_{2}$ uptake were observed; however, the associations between these two variables were not reported. ${ }^{6}$ The findings of our study extend the observations of previous investigations by providing evidence of the associations between pain and physiological measures of muscle strength and peak $\mathrm{VO}_{2}$ uptake.

Several related pathophysiological mechanisms may be responsible for our observed associations between lesser values of muscle strength and peak $\mathrm{VO}_{2}$ uptake, and greater scores of pain severity. First, muscle contraction can be partly impaired by pain because of the inhibiting effects that joint nociceptor stimulation has on motor neurons. ${ }^{26-28}$ Furthermore, anticipation of pain has been associated with alterations in the efficiency of motor unit activation. ${ }^{29}$ Second, previous studies suggest that differential activation of subpopulations of motor units in the trapezius muscle of patients with FM during monotonous contraction may be altered, ${ }^{30}$ and lower frequencies and greater duration of differential activation have been correlated with pain intensity. ${ }^{31}$ This is relevant because alterations in the differential activation of motor units have been posited to contribute to muscle fatigue and overexertion, ${ }^{32,33}$ and may represent an important peripheral mechanism for the maintenance of central sensitization. ${ }^{34-36}$ Indeed, similar mechanisms may partly explain the observations from our previous secondary analysis where greater isometric and isokinetic $\left(60^{\circ} / \mathrm{s}\right)$ knee strength were predictive of higher pressure pain thresholds. ${ }^{8}$

Regarding the potential mechanisms subserving the association between pain and peak $\mathrm{VO}_{2}$ uptake, alterations in microcirculatory capillaries in patients with FM have been reported, including reduced capillary density ${ }^{37,38}$ and blood flow. ${ }^{39-42}$ More specifically, capillary density has been correlated with the percentage of oxidative muscle fibers present in patients with $\mathrm{FM},{ }^{38}$ and lower blood flow responses during and following exercise have been observed ${ }^{42}$ These findings suggest that oxygen availability may influence the quantity of oxidative muscle fibers present in adults with $\mathrm{FM},{ }^{38}$ and muscle ischemia may be an important peripheral mechanism for maintenance of central sensitization. ${ }^{42}$

The observations from this study suggest several avenues of ongoing research. First, lesser values of isokinetic strength but not isometric strength were predictive of greater pain severity scores. Although it is not clearly evident why 
isokinetic but not isometric measures were associated with greater pain severity scores, previous studies suggest that the greater torque capacity of isokinetic testing ${ }^{43}$ and muscle tissue damage associated with fast contraction velocity ${ }^{44}$ may be important contributing factors. Second, further studies are needed to determine the associations between peak $\mathrm{VO}_{2}$ uptake and measures of capillary blood flow during and following exercise. Third, prospective studies are warranted to determine if physiologically derived values of strength and aerobic fitness would be suitable outcome measures for clinical trials aimed at investigating the impact of strength training and aerobic conditioning on FM-related alterations in central and peripheral processing of pain stimuli.

This study has some limitations. As previously reported, ${ }^{7,8}$ all patients in this trial were recruited following referral to a large tertiary medical center. However, the pain-related characteristics of patients admitted to our pain treatment program were comparable with those of a random sample of community-dwelling adults with chronic pain derived from the catchment area of our institution..$^{45}$ Strength of the quadriceps and hamstring groups were tested, but it should not be assumed that the associations reported in this study would be applicable to other muscle groups. Similarly, peak $\mathrm{VO}_{2}$ uptake was measured using one approach, and it should not be assumed that the associations reported in this study would be applicable to other measures of aerobic capacity.

\section{Conclusion}

The findings from this study extend the observations of our previously reported work. In our previous randomized equivalence trial, strength and aerobic exercise had equivalent effects on pain in patients with FM. ${ }^{7}$ In a subsequent analysis, greater isometric and isokinetic $(60 \%)$ knee strength was associated with higher pressure pain thresholds independent of pain severity and peak $\mathrm{VO}_{2}$ uptake. ${ }^{8}$ The observations from the current study suggest that lesser values of isokinetic knee strength and peak $\mathrm{VO}_{2}$ uptake were predictive of greater pain severity scores. Collectively, these studies provide an in-depth description of the interrelated effects that strength and aerobic fitness have on pain and pressure pain thresholds in adults with FM. However, ongoing investigations are needed to determine the longitudinal effects that strength training and aerobic fitness have on the pathophysiology of FM.

\section{Acknowledgment}

The research was conducted at the Mayo Pain Rehabilitation Center, Department of Psychiatry and Psychology, and the Translational Research Unit for Chronic and Acute Pain,
Department of Anesthesiology, Mayo Clinic, Rochester, $\mathrm{MN}$, USA, and was supported by a CR-20 grant from the Mayo Foundation.

\section{Author contributions}

WMH, JMS, and JSE designed the study. WMH and JMS performed the data analysis. WMH, JMS, JSE, DAO, WDM, and SMM wrote the manuscript. WMH was the principal investigator. All authors contributed toward data analysis, revised the manuscript, and agree to be accountable for all aspects of the work.

\section{Disclosure}

The authors declare that they have no competing interests in this work.

\section{References}

1. Harden RN, Revivo G, Song S, et al. A critical analysis of the tender points in fibromyalgia. Pain Med. 2007;8(2):147-156

2. Bachasson D, Guinot M, Wuyam B, et al. Neuromuscular fatigue and exercise capacity in fibromyalgia syndrome. Arthritis Care Res (Hoboken). 2012;65(3):432-440.

3. Goes SM, Leite N, Shay BL, Homann D, Stefanello JM, Rodacki AL. Functional capacity, muscle strength and falls in women with fibromyalgia. Clin Biomech (Bristol, Avon). 2012;27(6):578-583.

4. Valkeinen H, Hakkinen A, Hannonen P, Hakkinen K, Alen M. Acute heavy-resistance exercise-induced pain and neuromuscular fatigue in elderly women with fibromyalgia and in healthy controls: effects of strength training. Arthritis Rheum. 2006;54(4):1334-1339.

5. Dinler M, Diracoglu D, Kasikcioglu E, et al. Effect of aerobic exercise training on oxygen uptake and kinetics in patients with fibromyalgia. Rheumatol Int. 2009;30(2):281-284.

6. Redondo JR, Justo CM, Moraleda FV, et al. Long-term efficacy of therapy in patients with fibromyalgia: a physical exercise-based program and a cognitive-behavioral approach. Arthritis Rheum. 2004;51(2): 184-192.

7. Hooten WM, Qu W, Townsend CO, Judd JW. Effects of strength vs aerobic exercise on pain severity in adults with fibromyalgia: a randomized equivalence trial. Pain. 2012;153(4):915-923.

8. Hooten WM, Rosenberg CJ, Eldrige JS, Qu W. Knee extensor strength is associated with pressure pain thresholds in adults with fibromyalgia. PLoS One. 2013;8(4):e59930.

9. Mayo Clinic. Exercise for Fibromyalgia. Available from: http:// clinicaltrials.gov/ct2/show/NCT01253395. NLM identifier NCT01253395. Accessed March 14, 2014.

10. Wolfe F, Smythe HA, Yunus MB, et al. The American College of Rheumatology 1990 Criteria for the Classification of Fibromyalgia. Report of the Multicenter Criteria Committee. Arthritis Rheum. 1990;33(2):160-172.

11. Short KR, Vittone JL, Bigelow ML, et al. Changes in myosin heavy chain mRNA and protein expression in human skeletal muscle with age and endurance exercise training. J Appl Physiol. 2005;99(1): 95-102.

12. Kerns RD, Turk DC, Rudy TE. The West Haven-Yale Multidimensional Pain Inventory (WHYMPI). Pain. 1985;23(4):345-356.

13. Bernstein IH, Jaremko ME, Hinkley BS. On the utility of the West HavenYale Multidimensional Pain Inventory. Spine. 1995;20(8):956-963.

14. Rudy TE. Multiaxial Assessment of Multidimensional Pain Inventory: Computer Program User's Manual. 2nd ed. Pittsburgh, PA, USA University of Pittsburgh; 1989. 
15. Hooten WM, Townsend CO, Decker PA. Gender differences among patients with fibromyalgia undergoing multidisciplinary pain rehabilitation. Pain Med. 2007;8(8):624-632.

16. Hooten WM, Townsend CO, Sletten CD, Bruce BK, Rome JD. Treatment outcomes after multidisciplinary pain rehabilitation with analgesic medication withdrawal for patients with fibromyalgia. Pain Med. 2007;8(1):8-16.

17. Darchuk KM, Townsend CO, Rome JD, Bruce BK, Hooten WM. Longitudinal treatment outcomes for geriatric patients with chronic non-cancer pain at an interdisciplinary pain rehabilitation program. Pain Med. 2010;11(9):1352-1364.

18. Hooten WM, Mantilla CB, Sandroni P, Townsend CO. Associations between heat pain perception and opioid dose among patients with chronic pain undergoing opioid tapering. Pain Med. 2010;11(11):1587-1598.

19. Hooten WM, Sandroni P, Mantilla CB, Townsend CO. Associations between heat pain perception and pain severity among patients with chronic pain. Pain Med. 2010;11(10):1554-1563.

20. Miller TA, Allen GM, Gandevia SC. Muscle force, perceived effort, and voluntary activation of the elbow flexors assessed with sensitive twitch interpolation in fibromyalgia. J Rheumatol. 1996;23(9):1621-1627.

21. Tomas-Carus P, Gusi N, Hakkinen A, Hakkinen K, Raimundo A, Ortega-Alonso A. Improvements of muscle strength predicted benefits in HRQOL and postural balance in women with fibromyalgia: an 8-month randomized controlled trial. Rheumatology (Oxford). 2009;48(9):1147-1151.

22. Valkeinen H,Alen M, Hannonen P, Hakkinen A, Airaksinen O, Hakkinen K. Changes in knee extension and flexion force, EMG and functional capacity during strength training in older females with fibromyalgia and healthy controls. Rheumatology (Oxford). 2004;43(2):225-228.

23. Da Costa D, Abrahamowicz M, Lowensteyn I, et al. A randomized clinical trial of an individualized home-based exercise programme for women with fibromyalgia. Rheumatology (Oxford). 2005;44(11):1422-1427.

24. Gowans SE, deHueck A, Voss S, Silaj A, Abbey SE, Reynolds WJ. Effect of a randomized, controlled trial of exercise on mood and physical function in individuals with fibromyalgia. Arthritis Rheum. 2001;45(6): $519-529$.

25. Richards SC, Scott DL. Prescribed exercise in people with fibromyalgia: parallel group randomised controlled trial. BMJ. 2002; 325(7357): 185 .

26. Hodges PW, Mellor R, Crossley K, Bennell K. Pain induced by injection of hypertonic saline into the infrapatellar fat pad and effect on coordination of the quadriceps muscles. Arthritis Rheum. 2009;61(1):70-77.

27. Rice DA, McNair PJ. Quadriceps arthrogenic muscle inhibition: neural mechanisms and treatment perspectives. Semin Arthritis Rheum. 2010;40(3):250-266.

28. Schaible HG, Grubb BD. Afferent and spinal mechanisms of joint pain. Pain. 1993;55(1):5-54.

29. Tucker K, Larsson AK, Oknelid S, Hodges P. Similar alteration of motor unit recruitment strategies during the anticipation and experience of pain. Pain. 2012;153(3):636-643.
30. Gerdle B, Gronlund C, Karlsson SJ, Holtermann A, Roeleveld K. Altered neuromuscular control mechanisms of the trapezius muscle in fibromyalgia. BMC Musculoskelet Disord. 2010;11:42.

31. Holtermann A, Gronlund C, Roeleveld K, Gerdle B. The relation between neuromuscular control and pain intensity in fibromyalgia. J Electromyogr Kinesiol. 2011;21(3):519-524.

32. Falla D, Bilenkij G, Jull G. Patients with chronic neck pain demonstrate altered patterns of muscle activation during performance of a functional upper limb task. Spine (Phila Pa 1976). 2004;29(13):1436-1440.

33. Bawa P, Pang MY, Olesen KA, Calancie B. Rotation of motoneurons during prolonged isometric contractions in humans. J Neurophysiol. 2006;96(3):1135-1140.

34. Kosek E, Ekholm J, Hansson P. Modulation of pressure pain thresholds during and following isometric contraction in patients with fibromyalgia and in healthy controls. Pain. 1996;64(3):415-423.

35. Staud R, Nagel S, Robinson ME, Price DD. Enhanced central pain processing of fibromyalgia patients is maintained by muscle afferent input: a randomized, double-blind, placebo-controlled study. Pain. 2009;145(1-2):96-104.

36. Staud R, Robinson ME, Weyl EE, Price DD. Pain variability in fibromyalgia is related to activity and rest: role of peripheral tissue impulse input. J Pain. 2010;11(12):1376-1383.

37. Lindh M, Johansson G, Hedberg M, Henning GB, Grimby G. Muscle fiber characteristics, capillaries and enzymes in patients with fibromyalgia and controls. Scand J Rheumatol. 1995;24(1):34-37.

38. Srikuea R, Symons TB, Long DE, et al. Association of fibromyalgia with altered skeletal muscle characteristics which may contribute to postexertional fatigue in postmenopausal women. Arthritis Rheum. 2013;65(2):519-528.

39. Jeschonneck M, Grohmann G, Hein G, Sprott H. Abnormal microcirculation and temperature in skin above tender points in patients with fibromyalgia. Rheumatology. 2000;39(8):917-921.

40. Morf S, Amann-Vesti B, Forster A, et al. Microcirculation abnormalities in patients with fibromyalgia - measured by capillary microscopy and laser fluxmetry. Arthritis Res Ther. 2005;7(2):R209-R216.

41. Grassi W, Core P, Carlino G, Salaffi F, Cervini C. Capillary permeability in fibromyalgia. $J$ Rheumatol. 1994;21(7):1328-1331.

42. Elvin A, Siosteen AK, Nilsson A, Kosek E. Decreased muscle blood flow in fibromyalgia patients during standardised muscle exercise: a contrast media enhanced colour Doppler study. Eur J Pain. 2006;10(2):137-144.

43. Almosnino S, Brandon SC, Sled EA. Does choice of angular velocity affect pain level during isokinetic strength testing of knee osteoarthritis patients? Eur J Phys Rehabil Med. 2012;48(4):569-575.

44. Chapman D, Newton M, Sacco P, Nosaka K. Greater muscle damage induced by fast versus slow velocity eccentric exercise. Int $J$ Sports Med. 2006;27(8):591-598.

45. Watkins EA, Wollan PC, Melton LJ 3rd, Yawn BP. A population in pain: report from the Olmsted County health study. Pain Med. 2008;9(2):166-174.
Journal of Pain Research

\section{Publish your work in this journal}

The Journal of Pain Research is an international, peer-reviewed, open access, online journal that welcomes laboratory and clinical findings in the fields of pain research and the prevention and management of pain. Original research, reviews, symposium reports, hypothesis formation and commentaries are all considered for publication.

Submit your manuscript here: http://www.dovepress.com/journal-of-pain-research-journal

\section{Dovepress}

The manuscript management system is completely online and includes a very quick and fair peer-review system, which is all easy to use. Visit http://www.dovepress.com/testimonials.php to read real quotes from published authors. 